\title{
Consumer Perceived Risk and Technology Tools: the Reliability and Validity of Instrument
}

\author{
Nik Alif Amri Nik Hashim, Roslizawati Che Aziz, Shah Iskandar Fahmie Ramlee, Fauzan Hafiz \\ Muhammad Safri, Wan Farha Wan Zulkifli
}

\begin{abstract}
In the current era of the transition of technology, there have been changes in the way purchases are made by physical stores, but nowadays consumers are increasingly using online purchases that can be made anywhere. However, limited attention was paid to study the behaviour of online purchases which mainly focuses on young consumers in Kota Bharu, Kelantan. Therefore, using a quantitative approach, the currentpreliminaryresearchwas aimed atevaluating the soundness and consistency of the instruments used tomeasure the risk perception factors of online buying behaviour in Kota Bharu. A total of 100 samples were analysed using SPSS statistical software version 24. Precedingthe result, content and face validity, reliability, and normality data were checked by an expert. The result of the pilot study indicated that the measuring tools are consistentto be usedin this research, since rational normality has been proven by the data. The resultfrom the currentresearch presentedcompletebacking for the propositionedgaugingtoolsto be applied in futuresupplementarystudies.
\end{abstract}

Keywords: Young Consumer, Perceived risk, Internet Shopping, Behaviour

\section{INTRODUCTION}

$\mathrm{O}_{\mathrm{n}}$ nline shopping has been popular for many years, mainly because many customers feel comfortable to buy products either from home or the workplace. Online shopping is a priority for customers because the internet has been deemed a crucial implementation forinteractionsand businesses worldwide. In 2017, there were up to 4 billion internet users, which had increased by $57.7 \%$ compared to the number in 2000 [7]. The Asia region itself contributed about $49.2 \%$ of the total global Internet users. Additionally, around 1.66 billion persons worldwide had made online purchases in 2017, generating USD 2.3 million in internet sales. It is recognised that the rapid growth of Internet use leads to higher sales volume in the country. With access to computers connected to the internet, as well as portable computers and tablets, whether at the workplace, home, or through facilities

Revised Manuscript Received on December 15, 2019.

* Correspondence Author

Nik Alif Amri Nik Hashim*, Faculty of Hospitality, Tourism \& Wellness, Universiti Malaysia Kelantan, Malaysia. Email: nikalifamri@gmail.com

Roslizawati Che Aziz, Faculty of Hospitality, Tourism \& Wellness, Universiti Malaysia Kelantan, Malaysia. Email:roslizawati@umk.edu.my

Shah Iskandar Fahmie Ramlee, Faculty of Entrepreneurship and Business, Universiti Malaysia Kelantan, Malaysia. Email: shah@umk.edu.my

Fauzan Hafiz Muhammad Safri, Faculty of Hospitality, Tourism \& Wellness, Universiti Malaysia Kelantan, Malaysia. Email:fauzan.ms@umk.edu.my

Wan Farha Wan Zulkiffli, Faculty of Entrepreneurship and Business, Universiti Malaysia Kelantan, Malaysia. Email: farha@umk.edu.my like cyber cafes, cafes, and libraries, today the trend of online shopping has become a regular transaction.

Despite the rapid growth in e-commerce and online shopping, these exciting developments have led to several new challenges and problems involving major consumer data protection, payment security and enforcement, information disclosure, e-contract validity, product enforcement and quality [15]. Consumers considered that perceived risk is related to the process of decision-making when engagingin online purchasing or shopping. The perceived risk of consumers' buying online has been a vital issue for research as it will have a direct impact on customers' attitudes to online shopping;customers' viewpoints will contribute to a substantialeffecttoward their behaviour while shopping online [2]. As [1]pointed out, the perceived risks of online purchases will impact consumers' intent in a detrimental manner when they buy items through the internet. Thus, looking at the issues above, by conducting a pilot study, this current research attempts to scrutinise the proposed measurement scale in terms ofconsistency and soundness, and how it contributes to the perceived risk of online shopping. Validity and reliability are key objectives to ensure that inconsistency issues do not arise that may cause major research projects to fail.

\section{LITERATURE REVIEW}

Online shopping involves a user accessing the internet to search, select, buy, use, and dispose of goods and services, in satisfying their needs and wants. When people are performing online buying, they will face some risks. In fact, the consumers will perceive a higher level of risk when purchasing through the traditional method of purchasing as compare with Internet retail transactions [9]. As stated by [8], perceived risk is the possibility of loss in achieving a favourable outcome while consumers are doing online shopping, indicating individuals feeling of uncertainty with the possibility of a negative result in their online purchasing. With the advancement of the internet, the recognition of online shopping has increased [11] The online shopping activities has become the most third most beloved internet activity, and it is followed by e-mail usage or instant messaging and web browsing [10]. As lots of online shopping websites such as Lazada, Zalora and Shoppee are available on the internet, the youngsters are more likely to purchase online. Past studies were recognised that consumers buying intention are influenced by risk perception [2]. Thus, the consumers' attitude should be studied in relation to perceived risks and lead Malaysian to choose online transaction and give consequences to Malaysia Ecommerce development.

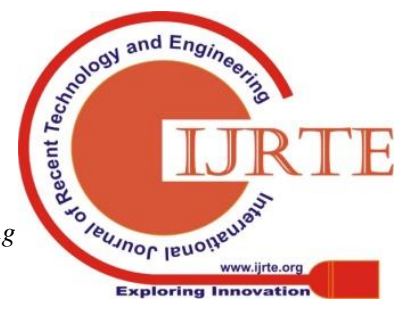




\section{Consumer Perceived Risk and Technology Tools: the Reliability and Validity of Instrument}

For this context of the study, five types of perceived risks were chosen, which are financial, physical, time, functional and social risk.

Financial risks are known as anyone is suffering from the payment of purchasing. The financial risks explain why online buyers easily believe the sellers in online; the buyers are doesn't think about the money [5]. Other than financial risk, consumers will also face physical risk in online buying. According to [4], physical risk defined as a risk faced by the consumer, which may that consumers will suffer a personal injury resulting by using of the purchased product. This risk will threaten the consumer in terms of the safety and health of the individual using the product [12]. On the other hand, the consumer will also be perceived by time risk. Time risk may refer to the loss of time and inconvenience incurred due to difficulty of navigation or submitting an order, finding appropriate websites, or delays receiving products [6]. Next is functional risk whereby it is related to the poor performance of a particular product. This can gain significance in the online environment, given the limited ability of buyers to examine the product carefully in term of colour, textures and robustness. For instance, when the retailer sells clothes through online, it is the possibility that the consumer is not satisfied with the product as it is not similar with the pictures in the website; thus this is known as functional risk. Last but not least is a social risk. Social risk is known as a community perception of consumers in making decisions on the purchase of goods [17]. The purchase decisions made by the consumer might be not accepted by other communities or the probability of family or friends going to be disapproval purchased product by the consumer [13].

\section{METHODOLOGY}

The current research employs a quantitative method, in which a questionnaire is used to conduct a pilot study. The process of data collection took place over the weekends in Kota Bharu. A number of 100 students were recruited to answer the pilot test questions using a self-administered questionnaire distribution. Data were analysed using IBM SPSS version 24 with Cronbach'sAlpha values calculated.

Moreover, normality tests have been verified to avoid statistical errors, which might yield invalid results. Both skewness and kurtosis tests were conducted, and the scores showed positive values. This indicates that the data are slightly sloped and peaked (leptokurtic) compared to the normal distribution (Std error), showing 0.416 for skewness and 0.791 for kurtosis. Both numbers are within the limits of \pm 1.96 , which means that the distribution in all combinations of constructs is normal, suggesting that departures from the normal are not too extreme.

With regard to the instrumentation, the pilot study was conducted among young consumers based on the developed questionnaire items. Seven parts were established, consisting of parts 1 to 7 . In Part 1, the questions are related to financial risk, while Part 2 consists of items related to physical risk. As for Part 3, the questionsare associated with the time risk variable, and Part 4 asks questions about functional risk. Next, Part 5 asks questions pertaining social risk and Part 6 relates to the internet shopping purchasing behaviour.
Finally, Part 7 asks six items on the demographic profile. The currentresearch instruments hadbeenmodified from precedingresearches, such as[3] and [14]. All question items were organized on a seven-point Likert's scale, which ranges from $1=$ very strongly disagree, to $7=$ very strongly agree.

Prior to the practical process of gathering data, this research tested its consistency and soundness. The use of reliability analysis is to test for the consistency and stability of responses. As suggested by [16], a reliability score below 0.6 is considered poor, while the score of 0.70 is considered good, and more than 0.8 is considered excellent. Scores for items below 0.70 were removed or refined. Besides, the researchers have ensuredvital precautions to confirm the validity of the scale's content. Accordingly, academics from two higher education institutions, namely Universiti Malaysia Kelantan and Universiti Teknologi MARA were asked to examine the validity of the questionnaire. Table 1 shows the outcomegained from the pilot study. Based on the acquired data, it is apparent that all measures produced high scores onreliability, as follows: financial risk (0.753); physical risk (0.712); time risk (0.723); functional risk (0.711); social risk (0.900); and internet purchase behaviour (0.706).This demonstrates a decent internal consistency. Instruments are considered to be average liabilities if they have coefficients of 0.60 and above [16]. As a result, the questionnaire can be considered as finalized, andcan be used to conduct future research.

\section{Table 1: The Cronbach's Alpha value of the questionnaire}

\begin{tabular}{|c|c|c|}
\hline \multirow{2}{*}{\multicolumn{3}{|c|}{$\begin{array}{l}\text { Consumer Perceived Risk towards } \\
\text { Behaviour }\end{array}$}} \\
\hline & & \\
\hline \multicolumn{3}{|l|}{ Part 1: Financial Risk } \\
\hline Cronbach's Alpha value & & 0.753 \\
\hline Total of items & & 5 \\
\hline \multicolumn{3}{|l|}{ Part 2: Physical Risk } \\
\hline Cronbach's Alpha value & & 0.712 \\
\hline Total of items & & 5 \\
\hline \multicolumn{3}{|l|}{ Part 3: Time Risk } \\
\hline Cronbach's Alpha value & & 0.732 \\
\hline Total of items & & 5 \\
\hline \multicolumn{3}{|l|}{ Part 4: Functional Risk } \\
\hline Cronbach's Alpha value & & 0.711 \\
\hline Total of items & & 5 \\
\hline \multicolumn{3}{|l|}{ Part 5: Social Risk } \\
\hline Cronbach's Alpha value & & 0.900 \\
\hline Total of items & & 5 \\
\hline \multicolumn{3}{|l|}{ Part 6: Internet shopping behaviour } \\
\hline Cronbach's Alpha value & & 0.706 \\
\hline Total of items & & 5 \\
\hline \multicolumn{3}{|l|}{ Part 7: Demographic Profile } \\
\hline Total of items & & 6 \\
\hline
\end{tabular}

\section{CONCEPTUAL FRAMEWORK}

Constructed from the prior literature, the conceptual framework was proposed to address the interrelationship between financial, physical, time, functional and social risk as the factors that influence internet shopping among young consumer. 


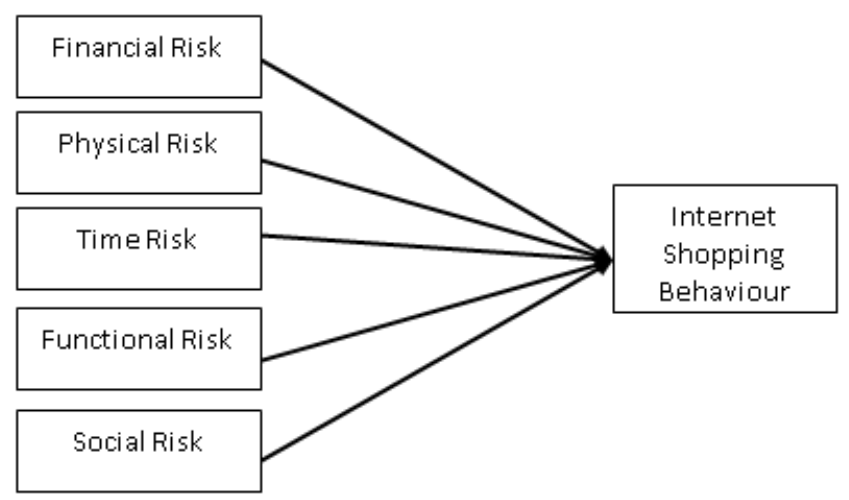

Figure 1: A Proposed conceptual framework

\section{CONCLUSION}

The aim of conducting this pilot study was to ascertain the soundness (validity) and consistency (reliability) of the measurement tools that will deliberately gauge the risk of online shopping among young customers before the actual research would be conducted. Pre-tests were conducted where expertsevaluated the subject matter and soundness of the questionnaire items. The findings from the reliability test indicate that the entire questionnaire is consistent, upon showing Cronbach's Alpha valuesof more than 0.7. This signifies that none of the items needs to be removed because they are considered acceptable. Furthermore, from the normal test values, the data is relatively normal, validating that the study protocol is feasible. Overall, the questionnaire was verified from the analysis of its "reliable and constructive" measures of validity. The actualresearch, which is expected to gather more than 380 respondents, could provide a glimpse into the risk perception of online shopping among young consumers, especially in the aspect of online shopping. It is hoped that the results of this study will contribute to the existing knowledge in relevant fields and are useful to authorities, retailers, and practitioners, in setting their marketing strategies within the retail industry. At the same time, this study will be a benchmark for upcoming research.

\section{ACKNOWLEDGMENT}

Thank you to the Faculty of Hospitality, Tourism, and Wellness, and the Faculty of Entrepreneurship and Business, Universiti Malaysia Kelantan for encouraging us to publish this paper.

\section{REFERENCES}

1. Almousa, M. (2011), "Perceived risk in apparel online shopping: a multi-dimensional perspective", Canada Social Science, 7(2), 23-21.

2. Ariff, M.S.M., Sylvester, M., Zakuan, N., Ismail, K. and Ali, K.M. (2014), "Consumer perceived risk, attitude and online shopping behaviour; empirical evidence from Malaysia", IOP Conference Series: Materials Science and Engineering, 58(1), IOP Publishing.

3. Ariffin, S.K., Mohan, T., \& Goh, Y.N. (2018). Influence of consumers' perceived risk on consumers' online purchase intention. Journal of Research in Interactive Marketing, 12(3), 309-327.

4. Chen, R., \& He, F. (2003). Examination of brand knowledge, perceived risk and consumers' intention to adopt an online retailer. Total Quality Management \& Business Excellence, 14(6), 677-693.

5. Egeln, L. S., \& Joseph, J. A. (2012). Shopping cart abandonment in online shopping. Atlantic Marketing Journal, 1(1), 1.
6. Forsythe, S. M., \& Shi, B. (2003). Consumer patronage and risk perceptions in Internet shopping. Journal of Business Research, 56(11), 867-875.

7. Internet World Stats (2018), "Internet usage in Asia", available at: www.internetworldstats.com/stats $3 . \mathrm{htm}$

8. Ko, H., Jung, J., Kim, J., \& Shim, S. W. (2004). Cross-cultural differences in perceived risk of online shopping. Journal of Interactive Advertising, 4(2), 20-29.

9. Lee, K. S., \& Tan, S. J. (2003). E-retailing versus physical retailing: A theoretical model and empirical test of consumer choice. Journal of Business Research, 56(11), 877-885.

10. Li, N., \& Zhang, P. (2002). Consumer online shopping attitudes and behavior: An assessment of research. AMCIS 2002 Proceedings, 74.

11. Lian, J.-W., \& Lin, T.-M. (2008). Effects of consumer characteristics on their acceptance of online shopping: Comparisons among different product types, Computers in Human Behavior, 24(1), 48-65.

12. Lu, H.-P., Hsu, C.-L., \& Hsu, H.-Y. (2005). An empirical study of the effect of perceived risk upon intention to use online applications. Information Management \& Computer Security, 13(2), 106-120.

13. Mitchell, V.-W. (1999). Consumer perceived risk: conceptualisations and models.European journal of marketing, 33(1/2), 163-195.

14. Nik Hashim, N.A.A., Yusoff, A.M., Awang, Z., Aziz, R.C., Ramlee, S.I.F., Bakar, N. A., Noor \& Fatt, B.S. (2019). The Effect of Domestic Tourist Perceived Risk on Revisit Intention in Malaysia. International Journal of Innovative Technology and Exploring Engineering (IJITEE),8(10),4591-4596.

15. Paynter, J. \& Lim, J. (2001), "Drivers and impediments to e-commerce in Malaysia", Malaysian Journal of Library and Information Science, $6(2), 1-9$.

16. Sekaran, U., Bougie, R. (2017). Research Methods for Business: A Skill Building Approach. United Kingdom: John Wiley \& Sons, Ltd Publication.

17. Ueltschy, L. C., Krampf, R. F., \& Yannopoulos, P. (2004). A cross-national study of perceived consumer risk towards online (Internet) purchasing. Multinational Business Review, 12(2), 59-82.

\section{AUTHORS PROFILE}

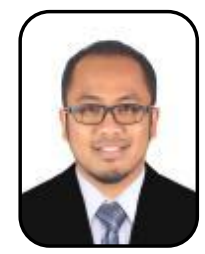

Nik Alif Amri Bin Nik Hashim is a lecturer in the Department of Tourism Management, Faculty of Hospitality, Tourism and Wellness, University of Kelantan Malaysia. He has been involved in research projects and published numerous articles nationally and internationally. His areas of expertise include Tourism and Hospitality Management, Travel Risk Perceptions, Destination Image, Travel and Tours, Tourism Technology, Tourism Event Management and Crisis \& Disaster Management. He is now taking a Doctor of Philosophy (PhD) focusing on Tourism \& Hospitality at the University of Queensland, Australia.

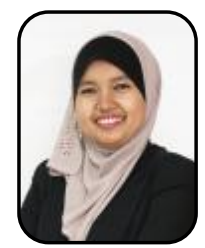

Roslizawati Che Aziz is a senior lecturer in the Faculty of Hospitality, Tourism and Wellness, Universiti Malaysia Kelantan. She holds a Doctor of Philosophy $(\mathrm{PhD})$ in Tourism Management from the Universiti Putra Malaysia. Her research contribution is mostly on Tourism Development, Tourism Management, Sustainable Tourism, Recreation, and Appreciative Inquiry. She has been actively involved in many projects related to community-based tourism projects, tourism education in $21^{\text {st }}$ century as well as leading a curriculum structuring program at her university.

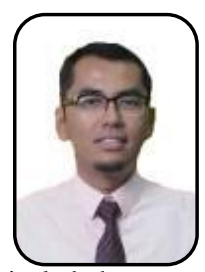

Shah Iskandar Fahmie Ramleeis a senior lecturer in the Faculty of Entrepreneurship and Business, Universiti Malaysia Kelantan.His research focuses are mainly in Entrepreneurship, Human Resource and Social Science. He holds a Doctor of Philosophy (PhD) from the Universiti Teknologi Malaysia.He has been involved in research projects and published numerous articles nationally and internationally. His areas of expertise include human resources management, entrepreneurship, innovation, small medium and enterprise management as well as technology information. 
Consumer Perceived Risk and Technology Tools: the Reliability and Validity of Instrument

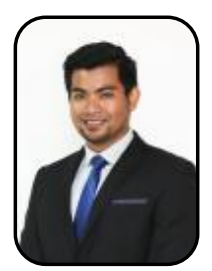

Fauzan Hafiz Muhammad Safri is an academician in the Faculty of Hospitality, Tourism and Wellness, Universiti Malaysia Kelantan. His research focuses are mainly in Hospitality and Tourism area. He holds a Master Degree from the Universiti Teknologi MARA, Malaysia. He has been involved in research projects and published numerous articles nationally and internationally. His areas of expertise include event management, tourism and hospitality management and tourism planning. He is currently purusing his $\mathrm{PhD}$ at Universiti Malaysia Kelantan which focused on event entrepreneurship and management.

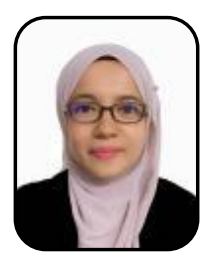

Wan Farha Wan Zulkiffliis a senior lecturer in the Faculty of Entrepreneurship and Business, Universiti Malaysia Kelantan.Her research focuses are mainly in Entrepreneurship, Business study and Social Science. She holds a Doctor of Philosophy (PhD) from the Universiti Teknologi MARA,Malaysia. She has been involved in research projects and published numerous articles nationally and internationally. Her research areas maindly focused on consumer behaviour, entrepreneurship development, innovation and entrepreneurship education. 